\title{
Understanding El Niño - The importance of Grey Literature in Coastal Ecosystem Research and Management
}

\author{
Sven Thatje ${ }^{\mathrm{a}, *}$, Jürgen Laudien ${ }^{\mathrm{b}}$, Olaf Heilmayer ${ }^{\mathrm{b}}$, Cornelia E. Nauen ${ }^{\mathrm{c}}$ \\ ${ }^{a}$ National Oceanography Centre, Southampton, School of Ocean and Earth Science, University of Southampton, European Way, \\ Southampton SO14 3ZH, UK \\ ${ }^{\mathrm{b}}$ Alfred Wegener Institute for Polar and Marine Research, Am Alten Hafen 26, D-27568 Bremerhaven, Germany \\ ${ }^{\mathrm{c}}$ Directorate General for Research (DG RTD), European Commission, 8, Square de Meeûs, SDME 1/20, B-1049 Brussels, Belgium
}

Received 17 March 2006; accepted 25 April 2006

\begin{abstract}
Access to information about past states of the environment and social systems is fundamental to understand, and cope with, the challenges of climate change and over-exploitation of natural resources at the onset of the 21 st century. The loss of (old) data is a major threat to understanding better and mitigating long-term effects of human activities and anthropogenic changes to the environment. Although this is intuitively evident for old and local literature of any kind, even present-day international publishing of papers without the underlying raw data makes access to basic information a crucial issue. Here, we summarise experience resulting from a EU-funded International Science \& Technology Cooperation (INCO) project (CENSOR) addressing Coastal Ecosystem Research and Management in the El Niño Southern Oscillation (ENSO) context. We show that indeed "Grey Literature" is still one of the most important sources of knowledge about natural science research and management of natural resource systems in Latin American countries. We argue that public archiving of original data of present-day research and old (Grey) Literature and easy public access are important for appreciating today's global environmental challenges caused by human activities, both past and present.
\end{abstract}

(C) 2006 Elsevier Ltd. All rights reserved.

Keywords: El Niño Southern Oscillation (ENSO); Artisanal fisheries; Humboldt Current; Coastal ecosystem management; Database; Climate oscillation

\section{Introduction}

The transfer of knowledge from one generation to another has been one of the main driving factors in the evolution of modern humans. Societal and technical advances in ancient cultures were strongly correlated with an increased archiving of information beyond an individual lifetime by the use of symbolic means in cultural traditions or in written language first arising in Mesopotamia about 4000 years ago as cuneiform letters. Today, with the rise and convergence of information technologies for miniaturised mass storage and commu-

\footnotetext{
*Corresponding author.

E-mail address: svth@noc.soton.ac.uk (S. Thatje).
}

nication, we do encounter a great variety and massive volumes of information every single day. The aggregation, selection, interpretation and use of what is important information is a challenge to everyone these days though algorithms and electronic media can and do help us to cope with this day-to-day exercise.

When looking back, however, one soon realises that public and scientific knowledge gained in the not so distant past is by far less dense and much less accessible than believed, especially if one tries to rely mostly upon information accessible by means of electronic sources. Indeed, that may lead to spurious interpretations as many of the ecosystems and trends evolve over much longer time spans than the very recent rise in electronic mass storage capacity. Aggregating, organising and 
interpreting the existing, yet dispersed, information is increasingly crucial for our understanding of fundamental changes taking place on Earth today. Attempts at pulling this dispersed information together to build greater knowledge about the structure and dynamics of large-scale systems are epitomised in research on climate change [1] and the world's ecosystems (see http:// www.millenniumassessment.org/en/index.aspx). Practices based on lack of understanding of these systems are, however, now creating conditions that endanger the future livelihood of a growing human world population. Looking at these challenges, the loss or non-awareness of existing, yet a sometimes unconventional source of information is unaffordable, both in the sense of weakened problem identification and solving capability and in terms of value for money.

We are aware of an increasing gap between understanding of researchers investigating the fundamentals of nature and society and the understanding of different social actors about the same phenomena, which are informed by history, socio-economic conditions and cultural preferences. The insufficient and sometimes impossible communication between these different "ways of knowing' is a major impediment for much needed increase of the scientific content in societal decisionmaking, which has been discussed elsewhere [2,3]. The present paper rather focuses on the upstream challenge of putting the science on broader footing. It has the twin objective to relate to and incorporate other sources of knowledge into a scientifically validated framework, while at the same time building bridges to the value- and knowledge systems of other social actors, thus enabling more inclusive and robust solutions.

\section{The challenges of scientific data archiving}

The lack of safe public archiving of scientific data by individuals or institutions has traditionally caused great losses of information over time [4,5]. The awareness by governmental institutions of the potential importance of data that might seem unimportant at a first view, but gain importance in a longer-term context of evolving conceptual approaches, is still astonishingly low [5]. This reflects insufficient institutional stability and institutional learning over extended periods of time in the case of ecosystem management and rapid climate change scenarios. Thus, if we (re-)start long-term monitoring programmes today without maintaining and further honing the ability to look as deep as possible into what used to be in the past, we can not ask many of the most essential questions associated with long-term dynamical change and suffer from shifting baseline syndrome [6].

Recently, scientific online databases have been proven to be effective means for the organised aggregation, structuring, dissemination and interpretation of infor- mation to the public at large $[4,7,8]$. We have even seen the beginning of creating a 'level playing field' in access to scientifically validated information and its transformation into knowledge that starts getting used in a wide range of applications outside the research process itself [9]. Although the development of such databases may not be as demanding in terms of public financial support as basic research, major challenges remain, e.g. in terms of:

(a) the increased number of online databases is still insufficient to fight against the loss of data taking place;

(b) more conceptual work is required to underpin collection, structuring and questioning capabilities in order the 'see the forest inmidst the trees'; and

(c) long-term institutional underpinning of these global public goods. Project-based financial support of databases does certainly not guarantee database development and maintenance beyond short-term funding schemes, still often resulting in stop-and-goactivities with frequent loss of information and knowledge as a result of such institutional crisis. Conversely, systematic accumulation of data and knowledge requires long-term commitment by both funding agencies and knowledge production and management institutions is necessary $[8,10]$.

Furthermore, Froese et al. [11] summarised that even successful initiatives face many challenges when data achieved through local funding agencies and/or institutional ownerships shall be made available to the public at large. Amongst a variety of concerns and legal problems highlighted [11] the loss of ownership, recognition of one's work, and economic issues can and should be addressed. Here, we present some experiences about the management of data and diverse publications in the El Niño Southern Oscillation (ENSO) context. Because of many previous problems of getting access to institutional data and building up confidence into a database system at international level, we would like to present a couple of mechanisms, which proved being a useful tool for guaranteeing continued ownership and effectively enhanced recognition of the work of a range of individuals and institutions made publicly available to the long-term benefit of all. We particularly describe and discuss the importance of "Grey Literature" in the ENSO context.

\section{Compilation of literature dealing with the subject ENSO}

Within the International Science \& Technology Cooperation (INCO) project CENSOR dealing with the coastal ecosystem of the Pacific Humboldt Current System 
under ENSO influence, more than 60 scientists from three South American and four European countries have compiled a literature database spanning the period from 1857 up to date. It provides access to a steadily increasing number of references and comprised 4.092 titles when this study was conducted (version available on November 30, 2005, at: http://www.CENSOR.name/ page/literature-related-to-enso/search-index.html). Literature was archived in a combined database accessible through the project's online ENSO reference manager. Data, however, relied upon individual reference databases of scientists involved, which in some cases were compiled over more than 25 years. The present database comprises moreover ISI literature, compiled from the "ISI Web of Knowledge ${ }^{\mathrm{SM}}$, Web of Science ${ }^{\circledR}$; WOS" (The Thomson Coorporation) and Aquatic Science and Fisheries Abstracts (ASFA, ${ }^{\circledR}$ CSA Information Company), and historical and so-called "Grey Literature" comprising local thesis work project reports, books and non-indexed journal publications of sometimes very limited number of copies.

Within ASFA and the WOS, we performed a search with the following criteria: "El Niño" (EN) or "La Niña" or "ENSO". This search resulted in about 5.743 references from which we excluded 1.651 studies dealing with the global consequences of ENSO outside the Humboldt-Current system.

The compiled ENSO database mainly consists of publications written in Spanish and/or English. References published in other languages, mainly French and German, make up $<0.5 \%$ of the total and were neglected in this study.

Each reference of the ENSO literature database was tcharacterized into two major scientific categories:

- organisms and ecosystems (including fisheries research and ecosystem management);

- climate change and physical environmental studies (including oceanography, geology, hydrology, glaciology)

and additionally distinguished into "Grey" or "ISI" as well as into "Spanish" or "English" within both scientific categories. Socio-economic literature was tentatively searched as well, but yielded too few references $(<0.3 \%)$ for a proper analysis at this stage. The part of the 'sustainability triangle' composed of environmental, social and economic dimensions need to be increased subject of future work.

\section{Results and discussion}

\subsection{Analyses of the ENSO literature database}

Our analyses restricts to ENSO literature dealing with the Humboldt Current Upwelling System off Pacific
South America, i.e. northern Chile, Peru, and Ecuador (Fig. 1). The procedure sometimes caused a problem in distinguishing relevant literature for this area from that of more global views on ENSO phenomenon, particularly in the field of climate research. However, a similar pattern in the categories "climate change and physical environmental studies" (more easily at larger scale) and "organism and ecosystem" (at Humboldt-Current System scale) (Fig. 3A and B) indicates that the possible bias of the selection criteria in the first can be neglected and that the overall pattern in both categories is rather a reflection of increased interest in ENSO and climate research in the early 1980s following the severe EN in 1981/82 [12] and around the turn of the millennium after the strong EN 1997-98 [13]. Some of the best data on climate impact available at present reflect that these two events were well documented [13-15]. Although we believe to have achieved a good reflection of ISIliterature from the ASFA and WOS search, the contribution of "Grey Literature" to ENSO research presented in this work is not believed to be comprehensive. It is very likely that we did not include all Grey ENSO literature and that the real contribution of "Grey Literature" to overall ENSO publications is indeed even higher than it is already the case in the present analyses (Fig. 4a and b). Retrieving this kind of literature and making it accessible, as a source for more robust scientific analysis, is an ongoing process.

\subsection{The importance of "Grey Literature" in ENSO research}

The ENSO phenomenon has received a great increase of interest since the severe EN in 1981/82, which is indicated by a steep increase in the number of publications of the following years (Fig. 2). This pattern is coherent in "organism and ecosystem, and "climate change and physical environmental studies", with a decline in publication activity during the early 1990s following the first peak of publications in 1985/86, which coincided with the 1987/88 EN event.

In the early 1990s output in both research areas declined in the Humboldt Current System but continuously increased since the year 2000. Thereafter ecosystem/organism studies diminished while climate change and physical environmental studies with local impact are still very popular (Fig. 3A and B). The internationalisation of climate research Versus ecosystem and organism studies in the area under investigation is obvious from the development of the "Grey Literature" contribution to both fields which also reflects the scales at which investigations are carried out.

"Grey Literature" contributed a high and constant share to organism and ecosystem studies focussing on the regional scale in the past 25 years $(>60 \%$ of all; more than $66 \%$ of "Grey Literature" is written in 


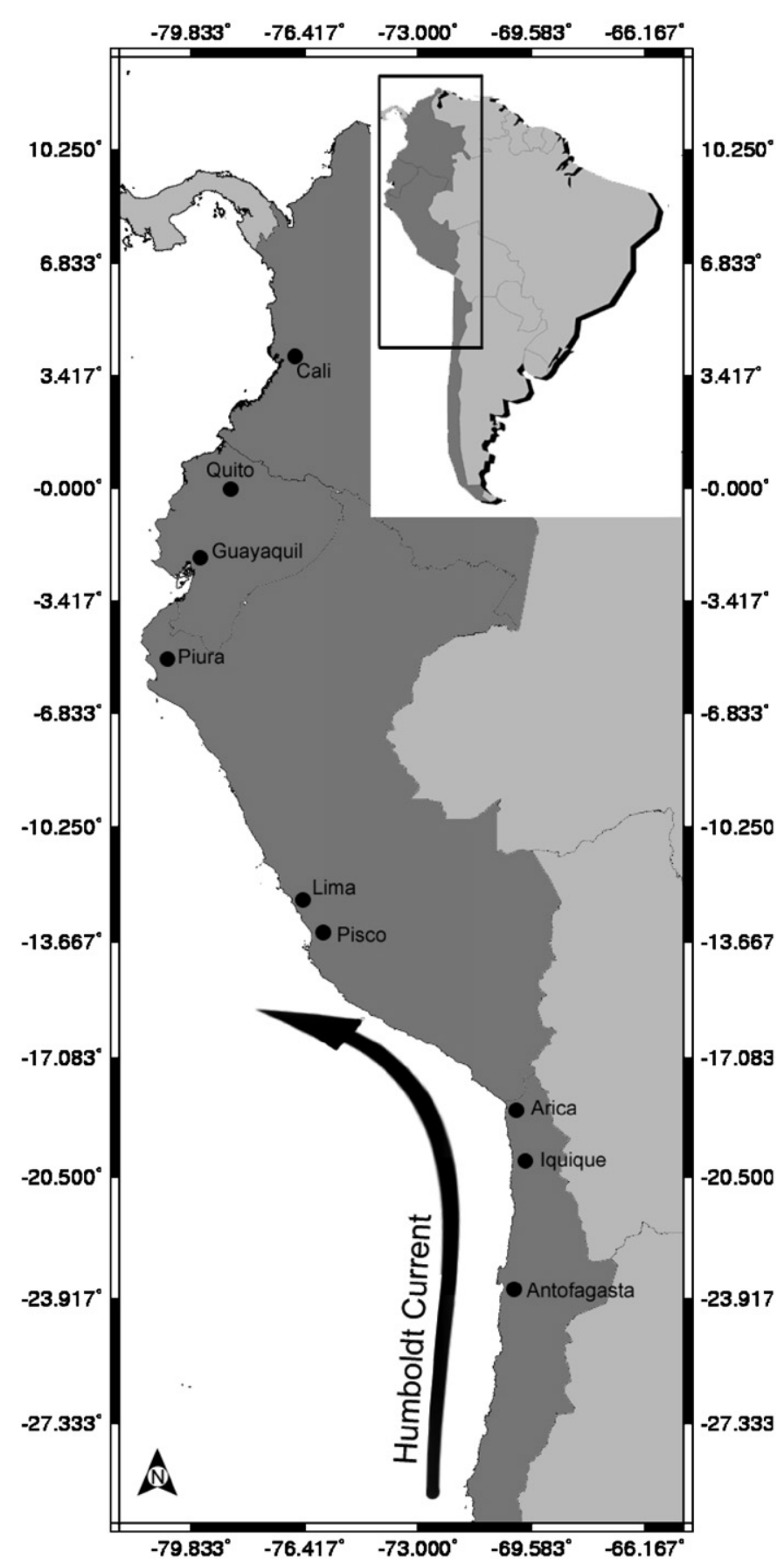

Fig. 1. The Humboldt Current Upwelling System off Pacific South America. The literature analysed in the present study deals with the primary impact countries of the ENSO, which are shown in the map (framed dark grey area).

Spanish), with a recent decline since the year 2000 (Fig. 4A). This points at another problem in disseminating the knowledge gained in "Grey Literature" at international scale — the language barrier - a big, but manageable challenge to databases, which needs more and specific attention. Whereas the language barrier might be manageable in database management in a longer perspective, it is striking at present that primary ISI journals rarely cite articles written in Spanish, which mostly represent "Grey Literature".
Although this observation may need further analyses, it might either be the citation policy in high-profile journals that discourage the citation of "Grey Literature", or a language barrier problem. The latter would not explain why Hispanic authors publish increasingly in English without making massive reference to publications in Spanish. From empirical experience we suggest that it may be a mixture of several factors with the positive element of creating a vast intellectual space with English effectively as the universal lingua franca in 


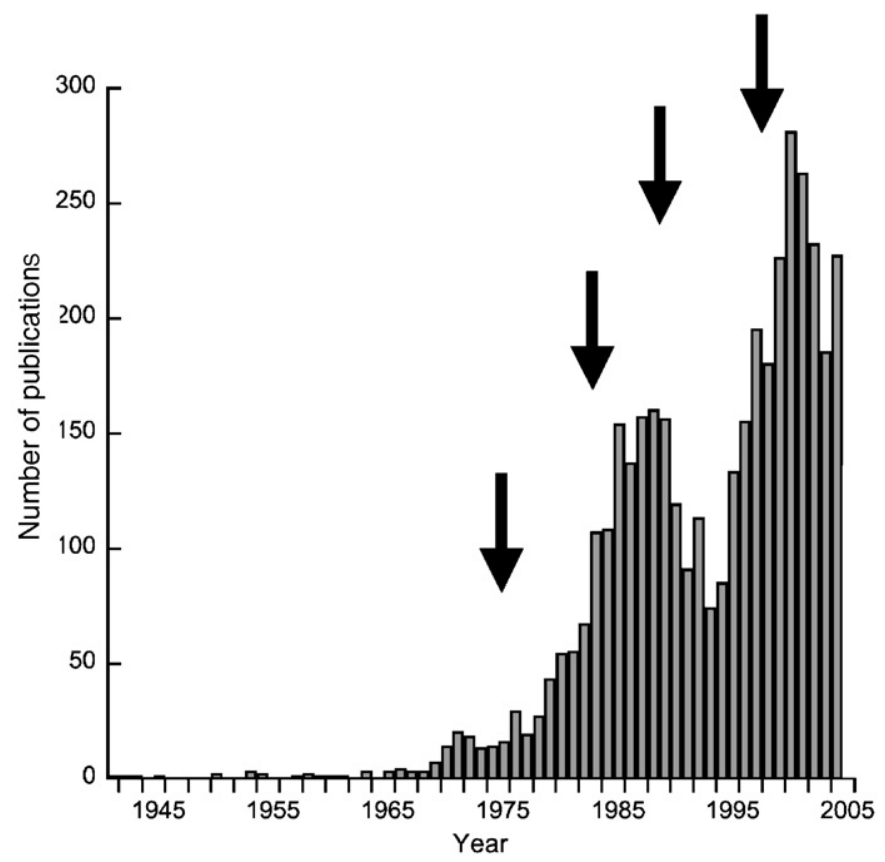

Fig. 2. Total number of ENSO literature (data from CENSOR literature database compiled until 30 November 2005; reference manager available at: http://www.CENSOR.name/page/literature-related-to-enso/search-index.html) for the Humboldt-Current area off Pacific South America $(N=4092)$.

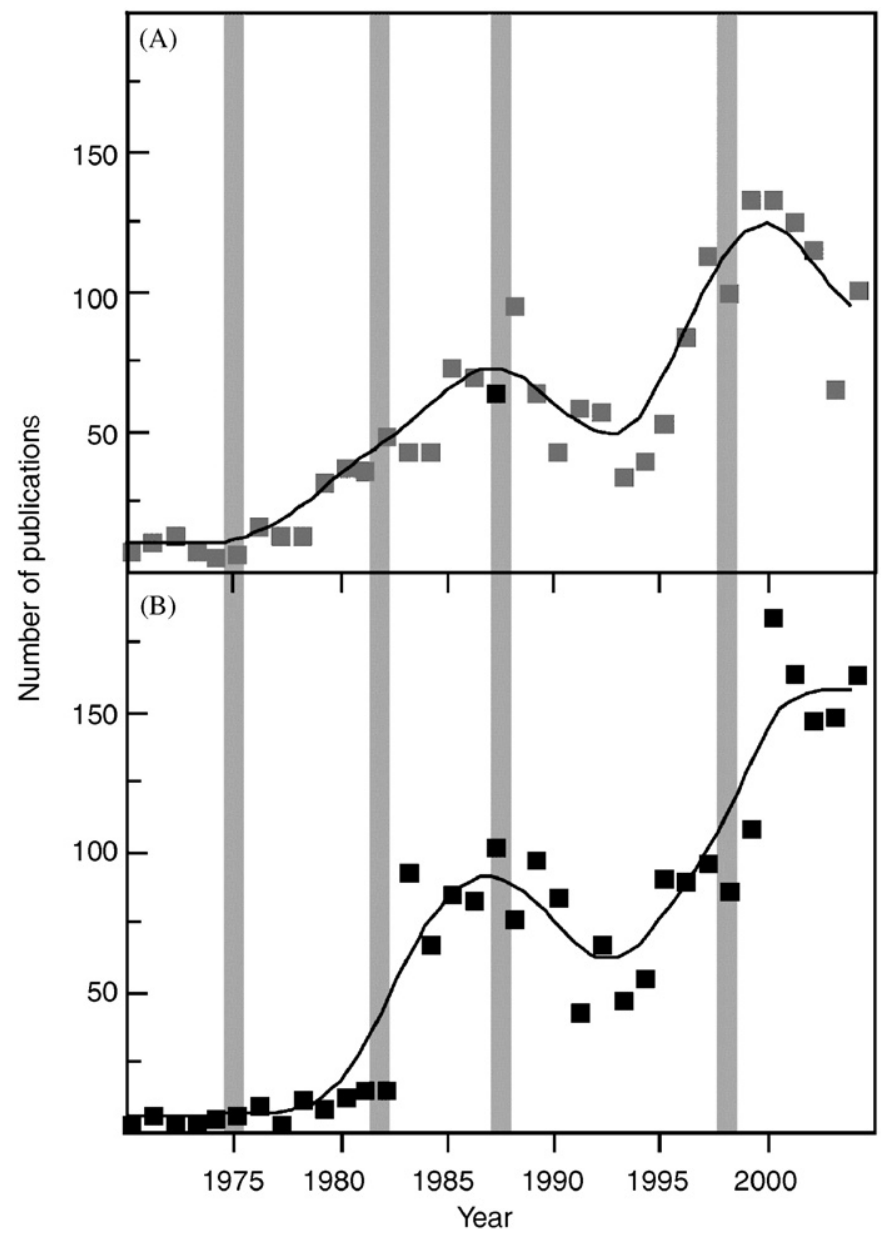

Fig. 3. The contribution of Grey Literature (NON-ISI) to ENSO literature of: (A) organisms and ecosystems and (B) climate change and physical studies. Trend lines are fitted with JMPv 5.1 and present a "smoothing spline fit $(\lambda=10)$ ". Grey bars indicate major El Niño events. 


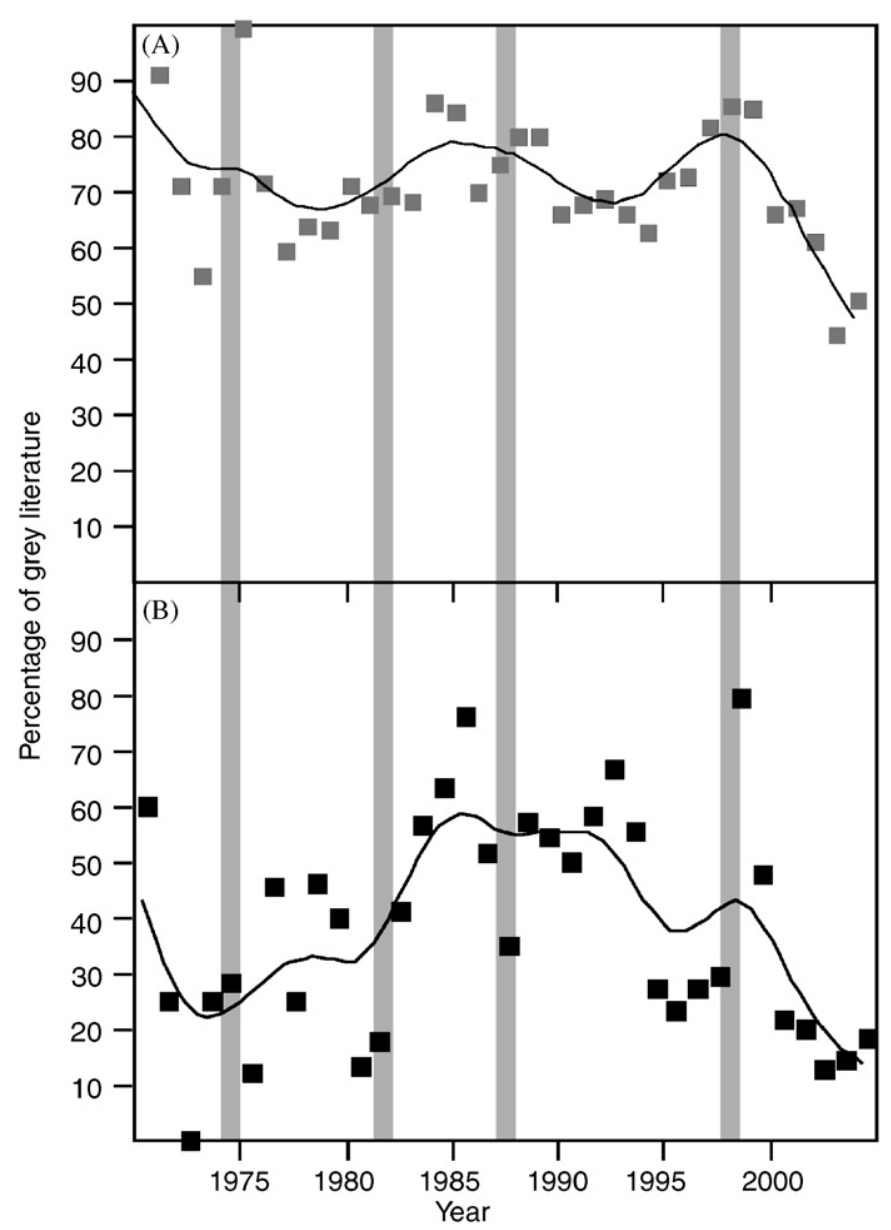

Fig. 4. Pattern of ISI/Grey Literature relationship in ENSO research in recent years (1970-2005) (data from literature database compiled until 30 November 2005, reference manager available at: http://www.CENSOR.name/page/literature-related-to-enso/search-index.html) in: (A) organisms and ecosystems and (B) climate change and physical environmental studies. Trend lines are fitted with JMPv 5.1 and present a "smoothing spline fit $(\lambda=10)$ ". Grey bars indicate major El Niño events.

the sciences, but with a shrinking space for scientific expression in other languages and a potentially growing gap between scientists and other citizens, especially those unfamiliar with English. Our quantitative analyses on the importance of "Grey Literature" do not reflect quality of scientific work. It is likely that peer-reviewed ISI journals, on average, achieve a higher and more reliable scientific standard. However, "Grey Literature" represents data and information that may still be very valuable in a comprehensive and long-term view, indeed, in some cases it may be the only source.

In the past, EN events have been the predominant driving factors in fostering research on the same (Fig. 2). It is striking, however, that the appearance of EN, which is of catastrophic proportions for the countries off Pacific South America and the coastal communities living there (e.g. [12]), is not reflected in coherent increase in socio-economic studies. It seems that ENSO knowledge in the natural sciences is not matched by equivalent study on the interaction between ENSO, ecosystems and society. Investigating such linkages appears by far more challenging and urgent than we had previously believed. The INCO-Programme's emphasis on integrated approaches will be useful here by 'forcing' the different disciplines and stakeholders to engage and cooperate actively.

The recent decline in "Grey Literature" since the year 2000 might be the result of increased pressure on scientists in South American countries to publish in ISI journals, as the economy of these countries is growing and higher education has become more and more an issue to catch up with the international community. This holds true as national, and especially international, funds are more readily allocated to scientists with a good publishing record in peer-reviewed journals and institutes are assessed against their ISIarticle contributions. Nevertheless, it should be noted that the declining publication trend coincides with a general decrease in publications in the field, which could be the result of decreasing overall funding.

Conversely, we observe a steady decline in the contribution of "Grey Literature" to climate research 
already starting in 1991 (Fig. 4B), indicative of international scale and standards associated with more funding from international agencies. Indeed, publications in journals such as Science, Nature, Journal of Climate Research, and the Journal of Geophysical Research, just to mention the most significant often cited ones here, are common in the field.

\subsection{The use of PANGAEA in archiving data from (Grey) literature}

Within the CENSOR project, we use the information system PANGAEA - Publishing Network for Geoscientific and Environmental Data (http://www. PANGAEA.de or via www.CENSOR.name) for archiving data related to ENSO research. Data are made available at the World Data Centre for Marine Environmental Sciences (WDC-MARE) using PANGAEA as its central data library [16-19]. Belonging to the ICSU system of World Data Centers, an international exchange of data on a long-term basis is ensured to assist scientists in working with comprehensive data collections. PANGAEA was originally developed to archive climate data coming from geology and glaciology, but has been subsequently made available to a wide range of biological and environmental data as well. Within the INCO-CENSOR project, this platform was improved for the use of biological data by complementing data archiving forms that allow the storage and use of a great variety of biological and oceanographic data. Data are retrieved from Grey Literature but also from any other data source comprising a great variety of biological, meteorological, oceanographic and socioeconomic parameters. Information on how to provide and use PANGAEA is given on the web portal.

Once data are provided to PANGAEA, the data set receives an identification number, the Digital Objective Identifier (DOI, http://www.idf.org). The DOI gives ownership to the originator(s) of the data. Authors, institutions, and funding sources are considered as well. CENSOR uses PANGAEA to store newly emerging data from ongoing research. In this case, the DOI is used to cite raw data in later publications, which allows the international scientific community to refer to the original data.

The DOI could be used to make original data of "Grey Literature" available to the public at large following publication, which in some cases could lie back years to decades. In this case, late credit is given to the author's work and ownership can be confirmed as well, even in the case of non-ISI publications. Of course, in many cases original data of such publications are not available anymore, but the "encoded" aggregated data given in a table or figure of the respective publication or report, can be retro-digitized. Like this, the DOI will save old data that might be at risk of getting lost, because of lack of copies or limited distribution outside its country of origin.

Most importantly, the user elsewhere in the world can be made aware that such data do exist and can be used. In this context, the electronic availability of data via the worldwide web (www) is fundamental for the dissemination and accessibility of information.

The use of old and long-term datasets considerably reduces time for analysis, cut research cost and, most importantly, increases the immediate evidence for trends and regime shifts in the environment. Recent significant insight into climate change and anthropogenic impacts on the environment based on long-term (old) data are, i.e., regime shifts in the marine trophic food web based on the over-exploitation effects of unsustainable fisheries [20-22], the importance of fisheries discards in the conservation of endangered seabirds [23] or long-term impact of climate change on the Southern Ocean food web in the 20th century, affecting the abundance of krill (Euphausia superba) to the benefit of salps (Salpa thompsoni) with potential consequences to the trophic web and marine resources [24], to mention just a few. Therefore, Dittert et al. [16] postulated the need for an internationally binding regulation that all scientific data are archived and freely accessible, coherent with WDC principles, to secure the world's stock of valuable data.

\section{Conclusion and perspectives}

- "Grey Literature" is dominating $(>70 \%)$ overall literature on organism and ecosystem ENSO studies in the Humboldt Current System, a tendency, which has remained surprisingly constant in the past few decades, despite efforts to connect local, regional and global scales, e.g. through the recent Millennium Ecosystem Assessment.

- "Grey Literature" written in Spanish is by far dominant $(>66 \%)$ in the field of organism and ecosystem research of the Humboldt-Current System. The language barrier and possible low dissemination rates into the wider international and English speaking community and ISI-literature, which needs increased attention.

- The CENSOR project is showing one possible way of archiving past and present original data by utilising PANGAEA and the DOI system, which allows for internationally identifying and guaranteeing the originator's rights. Like this, the DOI to original data can be used for archiving old data sets from local reports or "Grey Literature" as well as from ISI publications in journals or media that do not yet possess online archiving systems for raw data.

- It is essential that the various archiving systems already available worldwide, will be connected further and serve as an integrated public data archive 
via the worldwide web in line with the Aarhus Convention on Access to Information, Public Participation in Decision-Making and Access to Justice in Environmental Matters that entered into force in 2001 (see e.g. http://www.unece.org/env/pp/ documents/cep43e.pdf and http://europa.eu.int/ comm/environment/aarhus/).

- Duplication of efforts should be avoided to the benefit of available funding to science and increased interpretation of data. Therefore, it is necessary to take care that server systems are maintained on an open-ended basis by accountable and transparent governmental institutions, which are committed to the development and maintenance of global public knowledge goods.

- Funding agencies should take care that new data are supplied to already established systems, and that the hosting institution is committed to guaranteeing a long-term archiving of digital data far beyond the period of specially funded research projects. Such commitment should become part of international funding strategies in supporting World Data Centres and other appropriate mechanism to ensure a public information infrastructure with high potential to reduce transaction costs of doing science. This would also free resources for asking new questions in tune with evolving understanding and for new interpretation of more readily accessible information.

\section{Acknowledgements}

The CENSOR consortium is continuously putting effort into compiling an ENSO literature database and additionally a database of ENSO data stored at PANGAEA (http://www.Pangaea.de) publicly available for free (http://www.CENSOR.name). We acknowledge all CENSOR participants and especially the CENSOR database team: Ricardo Chero (ZMT, Bremen) and Dennis Steinhoff (AWI, Bremerhaven). CENSOR is financed through the INCO-DEV-FP6 programme and supported by the European Commission (Contract no. 511071), the Alfred Wegener Institute for Polar and Marine Research (Bremerhaven, Germany) and the "Consejo Nacional de Investigaciones Científicas y Técnicas" (CONICYT, Chile). This is CENSOR publication no. 0031.

\section{References}

[1] IPCC. Climate change 2001. Synthesis report. In: Watson, RT and the Core Writing Team, editors. A contribution of working groups I, II and III to the third assessment report of the intergovernmental panel on climate change. Cambridge, UK; New York, NY, USA: Cambridge University Press; 2001. 398pp. [www.ipcc.ch/]
[2] Gyawali D, Allan JA, Antunes P, Basim BA, Laureano P, Luiselli Fernández C, et al. EU-INCO water research from FP4 to FP6 (1994-2006) - a critical review, Office for Official Publications of the European Communities, Luxembourg, 2006. 86pp.

[3] Nauen CE, editor. Increasing impact of international S\&T cooperation. Luxembourg: Office for Official Publications of the European Communities; 2005. p. 28pp.

[4] Froese R, Reyes Jr R. Use them or lose them: the need to make collection databases publicly available. In: Legakis A, Sfenthourakis S, Polymeri R, Thessalou-Legaki M, editors. Proceedings of the 18th international congress of zoology, 2003. p. 585-91.

[5] Zeller D, Froese R, Pauly D. On losing and recovering fisheries and marine science data. Marine Policy 2005;29:69-73.

[6] Pauly D. Anecdotes and the shifting baseline syndrome of fisheries. Trends in Ecology and Evolution 1995;10:430.

[7] Froese R. The FishBase information system: key features and approaches. In: Feoli E, Nauen CE, editors. Proceedings of the INCO-DEV international workshop on information systems for policy and technical support in fisheries and aquaculture. ACPEU fisheries research report, vol. 8, 2001. p. 6-38.

[8] Sieger R, Grobe H, Diepenbroek M, Schindler U, Schlitzer R. International collection of JGOFS (Joint Global Ocean Flux Study), vol. 2: integrated data sets (1989-2003), WDC-MARE reports, vol. 3, 2005. 15pp., including CD-ROM.

[9] Nauen CE. Implementing the WSSD decision of restoring marine ecosystems by 2015 - scientific information support in the public domain. Marine Policy, in press.

[10] Pauly D. Importance of the historical dimension in policy and management of natural resource systems. In: Feoli E, Nauen CE, editors. Proceedings of the INCO-DEV international workshop on information systems for policy and technical support in fisheries and aquaculture. ACP-EU fisheries research report, vol. 8, 2001. p. 5-10.

[11] Froese R, Lloris D, Opitz S. Scientific data in the public domain. ACP-EU Fisheries Research Report 2004;14:267-71.

[12] Arntz WE, Fahrbach E. El Niño-Experimento Climático de la Naturaleza. Fondo de Cultura Económica, México, 1996; ISBN 968-16-5042-5.

[13] Tarazona J, Arntz WE, Castillo E. El Niño en América Latina: impactos biológicos y sociales. Lima: CONCYTEC; 2001. 423pp.

[14] Barber RT, Chávez FP. Biological consequences of El Niño. Science 1983;222:1203-10.

[15] Chávez FP, Strutton PG, Friederich GE, Feely RA, Feldman GA, Foley D, et al. Biological and chemical response of the equatorial Pacific Ocean to the 1997 and 1998 El Niño. Science 1999;286: 2126-31.

[16] Dittert N, Diepenbroek M, Grobe H. Scientific data must be made available to all. Nature 2001;14:393.

[17] Diepenbroek M, Grobe H, Schlitzer R, Sieger R, Siems U, Reinke M. Management of marine data with the PANGAEA-information system SEPAN, Marine science and technology programme, experiences in project data management. In: Bohle-Carbonell M, editor. MAST report, 1998. p. 297-309.

[18] Diepenbroek M, Grobe H, Reinke M, Schindler U, Schlitzer R, Sieger $R$, et al. PANGAEA - an information system for environmental sciences. Computers and Geosciences 2002;28: 1201-10.

[19] Grobe H, Diepenbroek M, Dittert N, Reinke M, Sieger R. Archiving and distributing earth-science data with the PANGAEA information system. In: Fütterer DK, Damaske D, Kleinschmidt G, Miller H, Tessensohn F, editors. Antarctica: contributions to global earth sciences. Berlin, Heidelberg, New York: Springer; 2006. p. 403-6. 
[20] Hutchings JA. Collapse and recovery of marine fishes. Nature 2000;406(6798):882-5.

[21] Pauly D, Christensen V, Dalsgaard J, Froese R, Torres F. Fishing down marine food webs. Science 1998;279(5352):860-3.

[22] Pauly D, Alder J, Bennett E, Christensen V, Tyedmers P, Watson R. The future for fisheries. Science 2003;302(5649):1359-61.
[23] Votier SC, Furness RW, Bearhop S, Crane JE, Caldow RWG, Catre $\mathrm{P}$, et al. Changes in fisheries discard rates and seabird communities. Nature 2004;427(6967):727-30.

[24] Atkinson A, Siegel V, Pakhomov E, Rothery P. Long-term decline in krill stocks and increase in salps within the Southern Ocean. Nature 2005;432(7013):100-3. 